\title{
EFEKTIFITAS DAN EFESIENSI PEMUNGUTAN PAJAKHOTEL DAN RESTORAN DALAM RANGKA MENINGKATKAN PENDAPATAN ASLI DAERAH KOTA BENGKULU
}

\author{
Budi Astuti $^{1}$, Diah Khairiah ${ }^{2}$, Yanyudi Anggara ${ }^{3}$ \\ ${ }^{123}$ Fakultas Ekonomi dan Bisnis UniversitasMuhammadiyah Bengkulu \\ Email :budiastuti@umb.ac.id, diahkhairiyah96@gmail.com
}

\begin{abstract}
ABSTRAK
Judul Penelitian ini adalah Analisis Efektifitas dan Efesiensi Pemungutan Pajak Hotel dan Restoran dalam rangka meningkatkan pendapatan asli daerah dikota bengkulu. Penelitian ini di dasari penting nya membayar pajak terutama pajak hotel dan restoran. Pendapatan Asli Daerah merupakan sumber pendapatan daerah yang secara bebas dapat digunakan oleh masing-masing daerah untuk menyelenggarakan pemerintahan dan pembangunan Daerah. Penelitian ini bertujuan untuk mengetahui efektifitas dan efesiensi pemungutan pajak hotel dan restoran terhadap pendapatan asli daerah (PAD) Kota Bengkulu.Jenis Penelitian ini menggunakan kualitatif dan kuantitatif, adapun jenis penelitian tersebut dapat diuraikan sebagai berikut: penelitian kualitatif yaitu data yang berupa penjelasan/ pernyataan yang tidak berbentuk angka. Data kuantitatif yaitu data penelitian yang berupa angkaangka.Dengan menggunakan teknik analisis data Efektifitas dan Efesiensi, hasil penelitian ini dapat disimpulkan bahwa pemungutan pajak hotel dan restoran di Kota Bengkulu Tahun 2017 sudah Efektif dan Efesien karena nilai tingkat efektifitas dan efesiensi pajak hotel dan restoran sebesar $82 \%$ dan $23 \%$.
\end{abstract}

Kata Kunci: Efektifitas, Efesiensi, pajak hotel dan restoran, PAD

\begin{abstract}
Title of this research is Analysis of Effectiveness and Efficiency of Hotel and Restaurant Tax Collection in order to increase the original income of the area in the city of Bengkulu. This research is based on the importance of paying taxes, especially hotel and restaurant taxes. Regional Original Income is a source of regional income that can be freely used by each region to organize regional government and development. This study aims to determine the effectiveness and efficiency of collecting hotel and restaurant taxes on local revenue (PAD) in the city of Bengkulu. This type of research uses qualitative and quantitative, while the type of research can be described as follows: qualitative research is data in the form of explanations / statements that are not numeric. Quantitative data, namely research data in the form of numbers. By using data analysis techniques Effectiveness and Efficiency, the results of this study can be concluded that the collection of hotel and restaurant taxes in the City of Bengkulu in 2017 effective and efficient because the value of the effectiveness and efficiency of hotel and restaurant tax is $82 \%$.
\end{abstract}

Keywords: Effectiveness, Efficiency, hotel and restaurant tax, PAD 


\section{PENDAHULUAN}

Otonomi daerah menghendaki daerah untuk berkreasi dalam mencari sumber penerimaan yang dapat membiayai pengeluaran pemerintah daerah dalam rangka menyelenggarakan pemerintahan dan pembangunan. Dalam Undang-Undang Nomor 28 Tahun 2009 tentang Pajak Daerah dan Retribusi Daerah, Pajak dan Retribusi daerah merupakan dua sumber Pendapatan Asli Daerah (PAD), disamping penerimaan dari kekayaan daerah yang dipisahkan serta PAD lain-lain yang sah. Semakin tinggi peranan PAD dalam pendapatan daerah merupakan cermin keberhasilan usaha-usaha atau tingkat kemampuan daerah dalam pembiayaan penyelenggaraan pemerintahan dan pembangunan.Dalam konteks pembangunan, Bangsa Indonesia sejak lama telah merancang suatu gerakan pembangunan yang dikenal dengan istilah pembangunan nasional. Pembangunan nasional adalah kegiatan yang berlangsung terus menerus dan berkesinambungan yang bertujuan untuk meningkatkan kesejahteraan rakyat baik yang bersifat material maupun spritual. Untuk itu pemerintah harus berusaha meningkatkan pendapatan dalam rangka mencapai tujuan pembangunan. Dalam menunjang keberhasilan pembanguan diperlukan penerimaan yang kuat, dimana sumber pembiayaan diusahakan tetap bertumpu pada penerimaan dalam negeri dan penerimaan dari sumber-sumber luar negeri hanya sebagai pelengkap. Kemandirian pembangunan diperlukan baik ditingkat pusat maupun ditingkat daerah, hal ini tidak terlepas dari keberhasilan penyelenggaraan Pemerintah Provinsi yang merupakan bagian yang tidak terpisahkan dari pemerintah pusat dengan kebijaksanaannya. Kebijakan tentang keuangan daerah ditempuh oleh pemerintah pusat agar pemerintah daerah mempunyai kemampuan membiayai pembangunan daerahnya sesuai dengan prinsip daerah otonomi yang nyata. Pendapatan asli daerah (PAD) merupakan sumber pendapatan daerah yang secara bebas dapat digunakan oleh masing-masing daerah untuk menyelenggarakan pemerintahan dan pembangunan daerah, tapi pada kenyataannya kontribusi pendapatan asli daerah terhadap pendapatan dan belanja daerah masih kecil. Selama ini dominasi sumbangan pemerintah pusat kepada daerah masih besar, oleh karenanya untuk mengurangi ketergantungan kepada pemerintah pusat, pemerintah daerah perlu berusaha meningkatkan pendapatan asli daerah (PAD) yang salah satunya dengan penggalian potensi daerah. Salah satu sumber pendapatan asli daerah (PAD) adalah pajak daerah di antaranya melalui pajak hotel dan restoran, oleh karena itu pemerintah daerah harus dapat mengupayakan peningkatan penerimaan yang berasal dari daerah sendiri sehingga memperbesartersedianyakeuangandaerahyangdapatdigunakanuntuk berbagai kegiatan pembangunan.

Salah satu sumber pajak daerah menurut Undang-Undang No. 33 tahun 2004 adalah pajak hotel dan restoran yang mana masing masing memberikan sumbangan pajak hotel sebesar Rp. 21.380.467 dan pajak restoran sebesar Rp.24.035.917 pada pajak daerah atau dengan kata lain pajak hotel dan restoran memberikan sumbangan rata rata $19 \%$ per tahun terhadap pendapatan pajak daerah Kota Bengkulu. Berdasarkandata statistik di Dinas Kebudayaan dan Pariwisata Kota Bengkulu, perkembangan jumlah hotel dan restoran mulai tahun 2012 sampai tahun 2017, terus mengalami peningkatan. Pada tahun 2012 sampai 2017 jumlah hotel dan restoran di Kota Bengkulu mengalami peningkatan dari tahun ke tahun, namun yang menjadi perhatian adalah sektor hotel dan restoran hanya memberikan kontribusi terhadap pendapatan asli daerah (PAD) Kota Bengkulu rata-rata sebesar $19 \%$ per tahun untukpajak daerah dan masih tergolong kecil.

Untuk itu pemerintah perlu berupaya meningkatkan penerimaan pajak hotel, agar penerimaan pemerintah terus meningkat sehingga dapat memperlancar pembangunan. Untuk mencapai ini pemerintah harus melakukan perbaikan dan penyempurnaan dalam bidang keuangan daerah yang dikelola secara efektif dan efesien. Dengan dasar pertimbangan ini, maka Pemerintah Kota Bengkulu harus secara aktif melakukan upaya pengembangan sumber-sumber pendapatan daerah yang salah satunya adalah pajak Hotel dan Restoran. 
Berdasarkan pemikiran dan keadaan tersebut, maka peneliti memilih judul "Analisis Efektifitas dan Efesiensi Pemungutan Pajak Hotel dan Restoran Dalam Rangka Meningkatkan Pendapatan Asli Daerah di Kota Bengkulu”.

\section{TINJAUAN LITERATUR}

\section{KonsepTeoriPajak}

Pajak adalah "Iuran rakyat kepada kas negara berdasarkan Undang-Undang (yang dipaksakan) dengan tiada mendapat jasa-timbal (kontra-prestasi), yang langsung dapat ditunjukkan dan yang digunakan untuk membayar pegeluaran umum". Dalam suatu jenis pajak kita akan mengenal istilah pajak proporsional, pajak progresif, dan pajak regresif yang tentunya berkaitan dengan masalah pendapatan. Suatu pajak akan disebut proporsional jika mengenakan tarif presentase yang sama tanpa melihat pendapatan seseorang. Sehingga setiap pembayaran pajak dikenakan tarif pajak dalam proporsi yang sama dari pendapatannya. Sedangkan untuk pajak progresif berbeda sama sekali dengan pajak proporsional.

\section{Pajak Daerah}

Pajak daerah merupakan pajak yang ditetapkan oleh pemerintah daerah dengan peraturan daerah, yang wewenang pemungutannya dilaksanakan oleh pemerintah daerah dan hasilnya digunakan untuk membiayai pengeluaran pemerintah daerah dalam melaksanakan penyelenggaraan pemerintahan dan pembangunan didaerah.

Jenis dan Tarif Pajak Propinsi adalah sebagai berikut.

a. Pajak kendaraan bermotor dan kendaraan diatas air 5\%

b. Bea balik nama kendaraan bemotor dan kendaraan diatas air $10 \%$

c. Pajak bahan bakar kendaraan bermotor $5 \%$

d. Pajak pengambilan dan pemamfaatan air bawah tanah dan air permukaan $20 \%$

Jenis dan Tarif pajak Kabupaten atau Kota adalah sebagai berikut.

a. Pajak Hotel $10 \%$

b. Pajak Restoran $10 \%$

c. Pajak Hiburan $35 \%$

d. Pajak Reklame 25\%

e. Pajak Penerangan Jalan $10 \%$

f. Pajak Pengambilan Bahan Galian Golongan C 20\%

g. Pajak Parkir $20 \%$

\section{Pajak Hotel}

Menurut Undang-undang No. 28 Tahun 2009 tentang Pajak Daerah dan Retribusi Daerah,Pajak Hotel adalah pajak atas pajak pelayanan hotel.Hotel adalah fasilitas jasa penginapan/ peristirahatan termasuk jasa lainnya dengan dipungut bayaran mencakup Motel, Losmen gubuk pariwisata,rumah penginapan dan sejenis nya. Menurut Peraturan Daerah Kota Bengkulu No 9 Tahun 2011 Pajak Hotel, yang selanjutnya disebut pajak adalah pajak atas pelayanan yang disediakan oleh Hotel. Hotel adalah fasiltas penyedia jasa penginapan/ peristirahatan termasuk jasa terkait lainnya dengan dipungut bayaran, yang mencakup motel, losmen, gubuk pariwisata, wisma pariwisata, pesanggarahan, rumah penginapan, guest housedan sejenisnya,serta rumah kos dengan jumlah kamar lebih dari 10 (sepuluh).

Pemungutan pajak hotel di Indonesia saat ini didasarkan pada dasar hukum yang jelas dan kuat sehingga harus dipatuhi oleh masyarakat dan pihak yang terkait. Menurut Suandy (2010), Objek pajak hotel adalah pelayanan yang disediakan oleh hotel dengan pembayaran, termasuk pelayanan sebagaimana di bawah ini:

a. Fasilitas penginapan atau fasilitas tinggal jangka pendek. 
b. Pelayanan penunjang sebagai kelengkapan fasilitas penginapan atau tempat tinggal jangka pendek yang sifatnya memberikan kemudahan dan kenyamanan.

c. Fasilitas olahraga dan hiburan yang disediakan khusus untuk tamu hotel, bukan untuk umum.

d. Jasa persewaan ruangan untuk kegiatan acara atau pertemuan di Hotel.

Pada pajak Hotel, yang menjadi subjek pajak adalahorangpribadi atau badan yang melakukan pembayaran atas pelayanan Hotel. Secara sederhana yang menjadi subjek pajak adalah konsumen yang menikmati dan membayar pelayanan yang diberikan oleh pengusaha Hotel. Sementara itu, yang menjadi wajib pajakadalahpengusaha hotel, yaitu orang pribadi atau badan dalam bentuk apapun yang dalam lingkungan perusahaanatau pekerjaannya melakukan usaha di bidang jasa penginapan. Dengan demikian, subjek pajak dan wajib pajak pada Hotel tidak sama. Dasar pegenaan Pajak Hotel adalah jumlah pembayaran yang dilakukan kepada hotel. Jika pembayaran dipengaruhiolehhubungan istimewa, harga jual atau penggantian dihitung atas dasar harga pasar yang wajar pada saat pemakaian jasa Hotel. Berdasarkan Undang-undang nomor 34 Tahun 2000 tarif pajak Hotel diterapkan paling tinggi sebesar sepuluh persendan ditetapkan dengan peraturan daerah kabupaten/ kota yang bersangkutan.

Besarnya pokok pajak Hotel yang terutang dihitung dengan cara megalikan tarif pajak dengan dasar pengenaan pajak. Secara umum perhitungan pajak hotel dalah sesuai dengan rumusberikut:

Pajak Terutang = Tarif Pajak $\mathrm{x}$ Dasar PengenaanPajak

$=$ Tarif Pajak x Jumlah Pembayaran yang Dilakukan Kepada Hotel

\section{PajakRestoran}

Menurut UU RI No. 34 Tahun 2000, restoran adalah tempat menyantap makanan dan minuman yang disediakan dengan dipungut bayaran, tidak termasuk usaha jenis tataboga ataucatering. Pajak restoran adalah pajakataspelayananrestoran.Pemungutan pajak restoran di Indonesia saat ini didasarkan pada Undang-undang Nomor 34 Tahun 2000yangmerupakanperubahan atas Undang-undang Nomor 18 Tahun 1997 tentang pajak daerah dan retribusi daerah dan Peraturan Pemerintah Nomor 65 Tahun 2001 tentang pajak paerah. Semula menurut Undang -undang Nomor 18 Tahun 1997 pajak atas hotel disamakan denganRestorandengan nama pajak Hotel dan Restoran. Akan tetapi, berdasarkan Undang undang Nomor 34 Tahun 2000jenispajaktersebutdipisahkan menjadi dua jenis pajak yang berdiri sendiri, yaitu pajak Hotel dan pajak Restoran.

Objek pajak Restoran adalah pelayanan yang disediakan restoran dengan pembayaran, termasuk dalam objek pajak restoran adalah rumah makan, cafe, bar, dan sejenisnya. Pelayanan direstoran/ rumah makan meliputi penjualan makanan dan atau minuman direstoran/ rumah makan, termasuk penyediaan penjualan makanan/ minuman diantar atau dibawapulang. Pada pajak Restoran yang menjadi subjek pajak adalah orang pribadi atau badan yang melakukan pembayaran kepada Restoran. Secara sederhana yang menjadi subjek pajak adalah konsumen yang menikmati dan membayar pelayanan yang diberikan oleh pengusaha Restoran. Sementara itu, yang menjadi wajib pajak adalah pengusaha Restoran, yaitu orang yang orang pribadi atau badan dalam bentuk apapun yang menjadi yang dalam lingkunganperusahaanatau pekerjaannya melakukan usaha di bidang rumah makan. Dengan demikian, subjek pajak dan wajib pajak pada Restoran tidak sama. Konsumen yang menikmati pelayanan Restoran merupakansubjekpajak yang membayar (menanggung) pajak sedangkan pengusaha restoran bertindak sebagai wajib pajak yang diberi kewenangan untuk memungut pajak dari konsumen (subjekpajak).

BerdasarkanUndang-undang nomor 34 Tahun 2000 tarif pajak Restoran ditetapkan paling tinggisebesarsepuluhpersen dan ditetapkan dengan peraturan daerah Kabupaten/ Kota yang bersangkutan. Besarnya pokok pajak Restoran yang terutang dihitung dengan cara mengalikan 
tarif pajak dengan dasar pengenaan pajak. Secara umum perhitungan pajak Restoran adalah sesuai dengan rumusberikut:

Pajak Terutang = Tarif Pajak $\mathrm{x}$ Dasar PengenaanPajak

$=$ Tarif Pajak x Jumlah Pembayaran yang Dilakukan Kepada Hotel

\section{Pendapatan Asli Daerah (PAD)}

Pendapatan Asli Daerah (PAD) merupakan sumber pendapatan daerah yang dapat dijadikan sebagai salah satu tolak ukur bagi kinerja perekonomian suatu daerah. Berdasarkan Undang-undang Nomor 32 Tahun 2004 tentang Pemerintahan Daerah dan Undang-undang Nomor 33 Tahun 2004 tentang Perimbangan Keuangan antara Pemerintah Pusat dan Pemerintah Daerah, pendapatan asli daerah (PAD) adalah pendapatan yang diperoleh daerah yang dipungut berdasarkan peraturan daerah sesuai dengan peraturan perundang- undangan, meliputi:
a. Pajak daerah;
b. Retribusi daerah;
c. Hasil pengelolaan kekayaan daerah yang dipisahkan;
d. Lain-lain PAD yang sah.

\section{METODE}

Penelitian ini dilakukan pada Badan Pendapatan Daerah Kota Bengkulu. Jl. Bentiring Permai Muara Bangka Hulu Kota Bengkulu. Adapun penelitian ini akan dilakukan pada Bulan Agustus 2018.Jenis penelitian menggunakan penelitian kuantitatif dan kualitatif.Teknik Pengumpulan Datadilakukandenganobservasi, wawancara, dokumentasi danstudiperpustakaan. Teknik analisis data dalam penelitian ini terdiri dari:

1. AnalisisDeskriptif

2. PerhitunganEfektifitasPemungutanPajak Hotel danRestoran

Dengan rumus:

Efektifitas $=\frac{\text { Realisasi penerimaan pajak hotel dan restoran }}{\text { Potensi pajak hotel dan restoran }} \times 100 \%$

3. Perhitungan Efesiensi Pemungutan pajak hotel dan restoran

Dengan rumus:

Efesiensi $=\frac{\text { Biaya pemungutan pajak hotel dan restoran }}{\text { penerimaan pajak hotel dan restoran }} \times 100 \%$

\section{HASIL DAN PEMBAHASAN \\ Efektifitas Pajak Hotel dan Restoran}

Tabel 1

Efektifitas Pajak Hotel dan Restoran Kota BengkuluTahun Anggaran 2012-2017

\begin{tabular}{|c|c|c|c|c|}
\hline No & $\begin{array}{c}\text { Tahun } \\
\text { Anggaran }\end{array}$ & $\begin{array}{c}\text { Target pajak hotel dan } \\
\text { restoran } \\
(\mathrm{Rp})\end{array}$ & $\begin{array}{c}\text { Realisasi Pajak } \\
\text { Hotel Restoran } \\
(\mathrm{Rp})\end{array}$ & Efektifitas \\
\hline 1 & 2012 & 5.520 .073 .920 & 4.292 .660 .204 & $77 \%$ \\
\hline 2 & 2013 & 8.586 .464 .000 & $7,803.214 .551$ & $91 \%$ \\
\hline 3 & 2014 & 11.229 .000 .000 & 9.902 .367 .272 & $88 \%$ \\
\hline 4 & 2015 & 12.378 .736 .000 & 10.223 .504 .825 & $83 \%$ \\
\hline 5 & 2016 & 17.379 .000 .000 & 13.194 .368 .208 & $75 \%$ \\
\hline 6 & 2017 & 18.000 .000 .000 & 14.778 .383 .582 & $82 \%$ \\
\hline
\end{tabular}


Dari tabel di atas terlihat bahwa tingkat efektifitas dari tahun 2012 - 2017 sudah cukup tinggi di tunjuk kan dengan tingkat efektifitas $82 \%$ pertahun nya.Hasil pengukuran menggunakan kategori nilai sebagai berikut:

1. Sangattidakefektif $(0-40 \%)$

2. Tidakefektif $(40 \%-60 \%)$

3. Cukupefektif $(60 \%-80 \%)$

4. Efektif $(80 \%-100 \%)$

5. Sangatefektif $(>100 \%)$

Sumber: Sidik (dikutip oleh Enggar, Sri Rahayu dan Wahyudi 2011)

Berdasarkan wawancara dengan Ibu Susi Susanti, S.Si,MM, adapun kendala-kendala yang di hadapi dalam memungut pajak di antara nya: wajib pajak yang kurang disiplin dalam membayar pajak atau tidak sesuai dengan waktu yang telah ditetapkan, sepi nya pengunjung sering di jadikan alasan oleh para wajib pajak, kurang sadar nya wajib pajak dalam membayar pajak, serta sektor kesejahteraan masyarakat yang akan berpengaruh terhadap pendapatan pajak hotel dan restoran ketika kesejahteraan masyarakat meningkat akan terjadi peningkatan pendapatan dan ketika kesejahteraan masyarakat menurun, pendapatan pun akan turun. Dalam rangka mengatasi kendala-kendala yang di hadapi petugas pemungut pajak hotel dan restoran, BAPEDA Kota Bengkulu melakukan beberapa upaya, upaya-upaya tersebut meliputi: di adakan nya sosialisasi terhadap pemilik hotel dan restoran, memnberikan pengarahan kepada pemilik restoran untuk melakukan promosi ditempat tempat wisata dan memasang iklan, objek pajak hotel dan restoran, kemudian upaya lain nya yaitu dengan penagihan langsung ke wajib pajak agar mengurangi besar nya tunggakan pajak.

\section{Efesiensi Pajak Hotel dan Restoran}

Tabel 2

Efisiensi Pemungutan Pajak Hotel dan Restoran Kota Bengkulu Tahun 2012-2017

\begin{tabular}{|c|c|c|c|c|}
\hline No & $\begin{array}{c}\text { Tahun } \\
\text { Anggaran }\end{array}$ & $\begin{array}{c}\text { Biaya pemungutan } \\
\text { pajak hotel dan } \\
\text { restoran (Rp) }\end{array}$ & $\begin{array}{c}\text { Realisasi pajak } \\
\text { hotel dan } \\
\text { restoran(Rp) }\end{array}$ & $\begin{array}{c}\text { Efesiensi } \\
(\%)\end{array}$ \\
\hline 1 & 2012 & 767.989 .000 & 4.292 .660 .204 & $18 \%$ \\
\hline 2 & 2013 & 1.606 .089 .000 & 7.803 .214 .551 & $20,58 \%$ \\
\hline 3 & 2014 & 1.990 .693 .000 & 9.902 .367 .272 & $20,10 \%$ \\
\hline 4 & 2015 & 2.380 .156 .000 & 10.223 .504 .825 & $23,28 \%$ \\
\hline 5 & 2016 & 3.670 .345 .000 & 13.194 .368 .208 & $27,82 \%$ \\
\hline 6 & 2017 & 4.098 .467 .000 & 14.778 .383 .582 & $27,25 \%$ \\
\hline
\end{tabular}

Dari tabel di atas terlihat bahwa tingkat efesiensi dari tahun 2012 - 2017 sudah cukup tinggi di tunjuk kan dengan tingkat efesiensi 23\% pertahun nya.

Pada tahun 2017 hotel yang patuhmembayarpajaksebanyak71 hotel, danyang tidak membayarpajaksebanyak 14 hotel. Sedangkanrestoran yang patuh membayar pajak restoran sebanyak 49 restoran dan yang tidak bayar sebanyak 3 restoran. Berdasarkan hasil wawancara dengan ibu Susi Susanti,S.Si, MM, selaku Plh. Kepala Badan Pendapatan Daerah Kota Bengkulu mengatakan bahwa alasan wajib pajak tidak membayar pajak hotel dan restoran karena rendahnya minat pelanggan membuat wajib pajak tidak bayar pajak dan terlalu tinggi target yang di tetapkan pemerintah dalam pemungutan pajak hotel dan restoran tanpa memperhatikan potensi yang ada. 
Kontribusi Pajak Hotel Dan Restoran Terhadaap PAD

Tabel 3

Kontribusi Pajak Hotel dan Restoran Terhadap Pendapatan Asli Daerah (PAD) Di Kota Bengkulu Tahun Anggaran 2012-2017

\begin{tabular}{|c|c|c|c|c|}
\hline No & $\begin{array}{c}\text { Tahun } \\
\text { Anggaran }\end{array}$ & $\begin{array}{l}\text { RPHR } \\
\text { (Rp) }\end{array}$ & $\begin{array}{l}\text { PAD } \\
\text { (Rp) }\end{array}$ & Kontribusi \\
\hline 1 & 2012 & 4.292 .660 .204 & 41.709.552.051 & $10 \%$ \\
\hline 2 & 2013 & 7.803.214.551 & 55.979 .830 .260 & $14 \%$ \\
\hline 3 & 2014 & 9.902 .367 .272 & 81.754 .841 .665 & $12 \%$ \\
\hline 4 & 2015 & 10.223 .504 .825 & 96.805 .458 .615 & $11 \%$ \\
\hline 5 & 2016 & 13.194 .638 .208 & 110.831 .838 .871 & $11 \%$ \\
\hline 6 & 2017 & 14.778 .383 .582 & 170.921 .364 .205 & $8 \%$ \\
\hline & Rata -rata & 60.194 .768 .642 & 558.002 .885 .667 & $11 \%$ \\
\hline
\end{tabular}

Berdasarkan hasil olah, besarnya kontribusi perhitungan pajak hotel dan restoran terhadap pendapatan asli daerah (PAD) di Kota Bengkulu Tahun anggaran 2012 - 2017 bervariasi mulai dari $8 \%-14 \%$ atau rata-rata $11 \%$ pertahun. Naik dan turun nya kontribusi pajak hotel dan restoran di pengaruhi banyak nya pengunjung serta jumlah wisatawan di Kota Bengkulu. Kontribusi terbesar terjadi pada tahun anggaran 2013 yaitu 14\% dan kontribusi terkecil terjadi pada tahun 2017 yaitu 8\%. Rata-rata kontribusi pajak hotel dan restoran terhadap pendapatan asli daerah selama enam tahun sebesar $11 \%$ dan dapat dikatakan asih relative kecil, akan tetapi cukup berarti dalam pembiayaan penyelenggaraan pemerintahan.

\section{PEMBAHASAN}

1. Kontribusi Pajak Hotel dan Restoran terhadap Pendapatan Asli Daerah di Kota Bengkulu.

Berdasarkan hasil perhitungan, besar nya kontribusi perhitungan pajak hotel dan restoran terhadap pendapatan asli daerah (PAD) Kota Bengkulu Tahun anggaran 2012-2017 bervariasi mulai dari $8 \%-14 \%$ atau rata-rata mengalami fluktasi pertahun, naik turun nya kontribusi pajak hotel dan restoran dikarena oleh banyak tidaknya kunjungan ke hotel dan restoran.

Kontribusi terbesar terjadi pada tahun 2013 yaitu 14\% dan kontribusi terkecil terjadi pada tahun 2017 yaitu 8\%. Pada tahun 2014 pajak hotel dan restoran mengalami penurunan $2 \%$ dari 14\% enjadi 12\%, pada tahun 2015 dan tahun 2016 kontribusi pajak hotel dan restoran turun menjadi 11\%,dan pada tahun 2017 kontribusi pajak hotel dan restoran turun menjadi $8 \%$, hal tersebut terjadi karena turun nya penerimaan pajak hotel dan restoran yang disebabkan oleh berkurang nya jumlah pengunjung hotel dan restoran serta jumlah hotel dan restoran di Kota Bengkulu.

2. Upaya Pemerintah Daerah Kota Bengkulu dalam meningkatkan Pendapatan Asli Daerah dari Pajak Hotel dan Restoran

Berdasarkan wawancara dengan Ibu Susi Susanti, S.Si,MM, upaya yang dilakukan Pemerintah Daerah Kota Bengkulu khususnya BAPEDA dalam meningkatkan pendapatan asli daerah (PAD) dari pajak hotel dan restoran adalah dengan peninjauan langsung ke hotel, restoran, rumah makan dan cafe-cafe. Peninjauan di lakukan untuk melihat apakah industri tersebut ramai atau tidak, dan sesuai atau tidak dengan pajak yang sudah dibayarkan selama bulan atau tahun berjalan, Peninjauan langsung tersebut tidak hanya dilakukan pada saat jam kerja atau di siang hari, tapi pada saat malam hari, hal ini karena industri hiburan seperti cafe, 
karoke dan bilyar dibuka malam hari, mengadakan pendataan ulang atau tertib administrasi di setiap hotel dan restoran untuk melihat perkembangan wajib pajak baik yang belum terdaftar maupun yang sudah terdaftar serta melakukan pengawasan terhadap wajib pajak apakah sudah membayarkan kewajibanya. Selanjutnya beliau juga mengemukakan untuk meningkatkan kontribusi pajak hotel dan restoran daerah di Kota Bengkulu tidak hanya tanggung jawab dari BAPEDA saja, tapi seharusnya ada kerja sama dari Pemerintah lainnya, misalnya Dinas Pariwisata, untuk mengupayakan agar mengupaya kan pengembangan pariwisata sehingga jumlah wisatawan selaku konsumen hotel dan restoran bisa lebih meningkat.

Dari paparan diatas, diketahui BAPEDA sudah berusaha secara maksimal, akan tetapi pemerintah daerah cenderung tidak mempertimbangkan pertumbuhan hotel dan restoran di Kota Bengkulu, dan tidak mempertimbangkan jumlah wisatawan di Kota Bengkulu, sehingga di setiap tahun terus meningkatkan target dari pajak hotel dan restoran. Untuk itu dalam menetapkan target penerimaan pajak hotel dan restoran perlu di dasari atas potensi hotel dan restoran di Kota Bengkulu, laporan income (pemasukan) dari wajib pajak, jumlah dan besarnya hotel dan restoran, jumlah pengunjung hotel dan restoran, perkembangan industry di bidang hotel. Sesuai dengan Perda No.5 tahun 1998 bab 3 tentang dasar pengenaan dan tarif pajak di dalam pasal 5 menyebutkan bahwa dasar pengenaan pajak adalah jumlah pembayaran pajak yang harus dilakukan hotel dan restoran dan pasa 16 menyebutkan bahwa tarif pajak ditetapkan sebesar 10\% (sepuluh persen). Pungutan pajak hotel minimum di Kota Bengkulu sebesar Rp. 300.000 per bulan dan pajak restoran sebesarRp. 300.000 per bulan.

\section{KESIMPULAN DAN SARAN \\ Kesimpulan}

Efektifitas pemungutan pajak hotel dan restoran terhadap pendapatan asli daerah (PAD) Kota Bengkulu Tahun anggaran 2012 - 2017 sudah Efektif karena nilai tingkat efektifitas sebesar $82,66 \%$.Efesiensi pemungutan pajak hotel dan restoran terhadap pendapatan asli daerah (PAD) Kota Bengkulu Tahun 2012 - 2017 sudah Efesien karena nilai tingkat efesien sebesar 23\%.Kontribusi pajak hotel dan restoran terhadap pendapatan asli daerah di Kota Bengkulu pada Tahun 2012 - 2017 sebesar 11\% pertahun nya.Upaya yang dilakukan Pemerintah Kota Bengkulu dalam meningkat kan penerimaan pendapatan asli daerah (PAD) dari sektor pajak hotel dan restoran meliputi mengadakan monitoring dan sosialisasi terhadap pemilik restoran dan hotel, mendata objek pajak hotel dan restoran mengada kan pendataan ulang/ tertib administrasi di hotel dan restoran untuk melihat perkembangan wajib pajak yang sudah ada kemudian melakukan penagihan langsung terhadap pajak hotel dan restoran.

Pemerintah Kota Bengkulu harus lebih intensif dalam melakukan komunikasi dan koordinasi dengan pihak terkait baik itu kepada dinas pendapatan, pengelolaan keuangan dan aset daerah, dinas pariwisata maupun pihak wajib pajak itu sendiri serta pihak-pihak lain supaya kerjasama yang saling menguntungkan antara semua pihak dapat terealisasi.

\section{DAFTAR PUSTAKA}

Abut Hilarius, 2007, Perpajakan, buku satu, cetakan pertama, Penerbit: Diadit Media, Jakarta.

Anita Candrasari, 2016. Kontribusi Pajak Hotel Dan Restoran Terhadap Peningkatan Pendapatan Asli Daerah Kota Surabaya. Jurnal ISSN 2460-0585.

Ardhiyansyah, Indra Widhi (2005), analisis kontribusi pajak hotel dan restoran terhaSdap pendapatan asli daerah Kabupaten purworejo Tahun 1989 - 2003, , FE UII, Yogyakarta.

Edward W. Memah, 2013. Efektifitas dan kontribusi penerimaan pajak hotel dan restoran terhadap PAD kota Manado. Jurnal ISSN 2303-1174. 
M. Husin, "AnalisisFaktor-Faktor yang mempengaruhi realisasi penerimaan pajak Hotel dan Restoran (studikasus pada Pemkot Surabaya)", FE UII, Yogjakarta.

M. Suparmoko, 1987. Keuangan Negara Dalam Teori dan Praktek, BPFE, Yogyakarta.

Mardiasmo. 2008. Perpajakan edisi Revisi 2008. Yogyakarta: Andi Offset.

Marihot P Siahaan, S.E 2005. Pajakdaerah dan RetribusiDaerahEdisiPertama, Jakarta. PT Raja Grafindo Persada.

Moljono Djoko dan Baruni Wijaksono, 2009, Akuntansi Pajak Lanjutan, edisipertama, Penerbit: Andi Yogyakarta.

Nugroho, Afriyanto (2000), "Analisis Faktor-Faktor yang mempengaruhi Pendapatan asli daerah (PAD) Kabupaten Dati II Klaten Tahun Anggaran 1983/ 1984-1999/ 2000”, FE UII, Yogyakarta.

Peraturan Daerah Kabupaten/ Kota yang mengatur tentang pajak Hotel.

Peraturan Daerah Kota Bengkulu No 09 Tahun 2011 Tentang Pajak Hotel.

Peraturan Pemerintah Nomor 65 Tahun 2001 tentang Pajak Daerah.

Resti, Siti. 2014. Perpajakan Teori dan Kasus Edisi 8 Buku 1, Penerbit Salemba Empat. Yogyakarta.

Siahaan, P. 2006. Pajak Daerah dan Retribusi Daerah. Jakarta: PT Raja Grafindo Persada.

Suandy Erly, 2010, Perpajakan, edisi kedua, cetakan kedua, Penerbit: Salemba Empat, Jakarta.

Supramono dan Thresia Woro Damayanti, 2010, Perpajakan Indonesia Mekanisme dan Perhitungan, edisi pertama, Penerbit: Andi: Yogyakarta.

Undang-undang nomor 34 Tahun 2000 tentang Pajak Daerah dan Retribusi Daerah. 